${ }^{\mathrm{I}}$ Universität Bielefeld, Alemanha

otthein.rammstedt@uni-bielefeld.de

Otthein Rammstedt'

\title{
COMO GEORG SIMMEL CHEGOU À MODERNIDADE E LHE PERMANECEU FIEL?
}

Tradução de Markus Hediger Revisão técnica de Leopoldo Waizbort

No final do século XIX, a sociologia conseguiu ser reconhecida como disciplina científica, iniciando assim, ao mesmo tempo, a sua institucionalização: formaram-se associações sociológicas, revistas dedicadas a este tema foram publicadas e a sociologia reivindicou seu lugar no circuito das disciplinas acadêmicas. Émile Durkheim (I858-I9I7), Georg Simmel (I858-I9I8) e Max Weber (I864-I920) são considerados hoje os pais fundadores dessa sociologia científica, e estamos acostumados a falar dela como "sociologia moderna".

É uma expressão que usamos de modo recorrente, mas que deveria nos fazer refletir se nos conscientizássemos que "moderno" significa "agora", "no presente" em oposição ao passado: "moderni" versus "antiqui". Ao mesmo tempo, porém, deveríamos nos lembrar que a sociologia se iniciou numa fase que, por volta de I890, era designada de "modernidade" e que era, na época, percebida como um tempo de revolução social. A sociologia e o discurso sobre a modernidade se determinavam reciprocamente, e um dos representantes dessa imbricação foi Georg Simmel.

Nenhum outro sociólogo daquele tempo foi considerado tão "moderno" quanto Simmel em sua vida cotidiana e em suas atividades como escritor e cientista. Em seu dia a dia, Georg Simmel jogava tênis, patinava no gelo e praticava alpinismo, gostava de viajar e andar de bicicleta - ele "costumava vir para a universidade de calças curtas e de bicicleta, recém-surgida e de má fama para pessoas de boa educação", lembra-se uma estudante (Landmann, 
I958: 208) -, ele fumava cigarros, gostava de um bom vinho, era excelente pianista com uma paixão frustrada pela poesia - "eu não era poeta, não era poeta", ele lamenta (Simmel, 2005 [1900]: 402) - e amava o debate - "e, quando falava, Simmel era sempre vitorioso, reconheceu Fritz Mauthner em seu obituário (Mauthner, I9I8). Como cientista, criticava a moral retrógrada em relação à opressão da mulher, na questão da prostituição, nas condições de trabalho do proletariado; lutou contra o espiritismo, contra o pessimismo revigorado e as ideias dos novos ricos, tanto em jornais conservadores como social-democratas e, em seus pequenos trabalhos científicos, oscilava desnorteado entre a crítica literária, a filosofia da arte, a ética, a psicologia dos povos e a sociologia. Tudo isto foi colocado à prova e ganhou estrutura quando, na década de i880, Simmel entrou em contato com o Naturalismo por meio de seu círculo de amigos desde os anos de faculdade. No Naturalismo encontrou seu lema com o termo "a modernidade", criado em I8962 - "nossa nova imagem de Deus" (Eugen Wolff apud Schutte \& Sprengel, I987: I8).

O Naturalismo remete, aqui, primeiramente a uma vertente literário-estética criada por Émile Zola (I840-I902), Henrik Ibsen (I828-I906) e Fiódor Michailowitsch Dostoiévski (I82I-I88I), que, na década de I880, conseguiu se impor a partir de seus centros Paris e Berlim (Bertaux \& Bertaux, I98I: 250-264). Em nome da veracidade, o Naturalismo exigia uma representação da natureza como fenômeno acessível à experiência sensível e ampliou-se, transformando-se em um movimento de protesto social que encontrou muitos adeptos entre aqueles que, nascidos após I860 (ver Schutte \& Sprengel, I987: I6), ${ }^{3}$ haviam vivenciado de forma consciente a fundação do Reich alemão recém-constituído, ou a Comuna em Paris e o início da Terceira República. Porém, ao contrário de Paris, Berlim transformou-se em metrópole apenas a partir da década de I870: entre I87I e I895, sua população cresceu de 825 mil para I,7 milhão de habitantes, a industrialização se propagou rapidamente e a oposição entre capital e trabalho tornou-se evidente. O poeta Hermann Conradi (1862-I890), uma das mentes mais importantes do Naturalismo berlinense, queria sentir esses "antagonismos" "em todo o seu ímpeto e plenitude trágicos, em seus meios de expressão mais penetrantes [e] tentar exprimir criativamente, com plena entrega e paixão, os diferentes graus e matizes do ajuste de contas com a enorme confusão do tempo" (apud Lange, I984: 692).

O movimento de protesto acusava, consequentemente, a miséria social e recusou as ideias dos antiquados representantes da arte, literatura, ciência e política, querendo substituí-los por algo novo - por ora apenas vislumbrado. As proclamações desse movimento social são de natureza literário-estética, porém, ao acatar as últimas conquistas científicas do darwinismo, do monismo e do socialismo naturalisticamente evolucionários (Bertaux \& Bertaux, I98I: 258), o movimento se capacitou para "explicar todo o físico sem recorrer 
a princípios espirituais" (Simmel, 2000 [189Ia]: 274), ${ }^{4}$ e se apresentava como uma nova "visão do mundo", a exigir "primeira e principalmente" uma "reconfiguração da sociedade humana" (Anônimo [1888] apud Schutte \& Sprengel, I987: 187). E, assim, acreditavam estar diante de uma revolução irrefreável, na qual confiavam ainda mais quanto mais partiam do pressuposto de que os adversários do novo eram os não-modernos - ou seja, eram de ontem e estavam ultrapassados. Acreditavam que somente o presente poderia caracterizar um novo realmente moderno, algo que não era um desenvolvimento, mas, sim, uma criação, que não possuía história e que se impunha por si mesmo - o que se manifestava em seu conceito afirmativo "modernidade" e que tinha em "antiguidade" o seu conceito opositor (Anônimo [1888] apud Schutte \& Sprengel, I987: I87).

Essa crítica social e cultural apresentada com tanta veemência tornou-se uma questão de valor pessoal para Simmel. Em I902, em um ensaio escrito apenas em inglês, ele lembrou que, na década de I880, a "justiça social", de uma hora para outra, se tornara um ideal onipresente:

De repente nos conscientizamos das condições de vida miseráveis do proletariado, que praticamente clamava ao céu, da exploração da classe dos trabalhadores, da injustiça que sofriam, da destruição de sua vida familiar, de sua degeneração física e mental, sobretudo de suas consequências para o trabalho feminino e infantil.

Tudo isso despertou nele uma "consciência social" (Simmel, 2010 [1902]: I75 Ss.) que então o motivou a denunciar as condições sociais, o falso pudor e a mentira moral da burguesia. "Entre as manifestações mais eficazes do nosso movimento social está a peça 'Die Weber' [Os tecelões], de Hauptmann”, escreve Simmel na introdução à sua resenha dessa peça de maior sucesso do Naturalismo (Simmel, 2005 [1893]). Ela "expressa as mais profundas vertentes", em relação às quais toda "expressão de vida moderna [...] precisa se adaptar"; a exposição da miséria dos tecelões no palco não seria agitação, tampouco apenas a aplicação de cogitações naturalistas. Hauptmann estaria interessado, como este lhe confessara, "exclusivamente no problema poético". Mas, justamente, isso servia a Simmel como prova do "poder daquele movimento", pois mostrava "que a miséria das massas e seu desejo de salvação já havia penetrado as fontes ocultas e inconscientes da imaginação poética"; ela representava o "ímpeto penetrante" do movimento naturalista (Simmel, 2005 [1893]: 26).

A partir do final da década de 1880 , Simmel se considerou parte do movimento naturalista, que ele também chamou de "movimento de uma nova cultura" (Simmel, 2000 [I89Ia]: 280). E, a partir de então, passou a usar o adjetivo "moderno" - "visão moderna de mundo" (Simmel, 2000 [I891a]: 279), "cientificismo moderno" (I989 [I890]: II2), "visão moderna da vida" (2008 [I89I]: 56), e até mesmo "a mais moderna visão da vida" (2000 [1891a]: 273), 
"espírito moderno" (I995 [I903]: II6, II9), "formação moderna do espírito" (I989 [I888]: 20), "vida moderna do espírito" (2000 [I89Ib]: 304), "tempos modernos" (2000 [I890]: 239) - sempre referido ao "novo", que se iniciou nos anos I880 e incluiu a década de 1890 , com suas expectativas de revolução. E ele buscou refletir filosoficamente sobre o "novo" e constatou, nesse contexto, que o positivismo, que há muito se manifestara nas ciências naturais, agora se ampliara, e acabava encontrando sua realização no Naturalismo. As coisas materiais seriam os objetos a serem analisados e cuja essência precisaria ser apreendida (Simmel, 2010 [1902]: I96). A isto corresponde a seguinte formulação de um aluno de Simmel:

Finalmente, então, surge a era em que as coisas são tratadas com o devido respeito,
em que palavras e conceitos são reconhecidos e cultivados como meios, mas sem
serem supervalorizados. [...] Nossos deuses são as coisas. As coisas singulares. [...]
Queremos apreender as coisas com cuidado e com sentidos infinitamente apurados,
queremos espreitá-las, surpreendê-las, com suas cores e sombras fixas, queremos
captar a hora, o momento, delicados como a borboleta. [...] Por isso, nós, como artistas
e estudiosos, retornamos aos sentidos. De forma alguma queremos ver demais, não
queremos mentir para nós mesmos. Essa modéstia profundamente reverenciosa é o
realismo (Sheu, I898: 92 ss.).

Simmel, porém, sabia que ninguém se torna parte de um movimento apenas confessando seus ideais - pois um movimento não é organização formal, com seus membros e suas metas definidas. Antes, as produções artísticas e científicas, as ideias políticas, as autocertificações culturais são partes do movimento naturalista que, em situação de concorrência, oferece como ideologia algo comum à época na apreensão e na elaboração do mundo e da vida, ${ }^{5}$ pretendendo realizar a "modernidade". Por isto Simmel elegeu "l'art pour l'art" como a palavra de ordem do Naturalismo, com o que se destacava a independência do artista e sua responsabilidade diante de seu sentimento artístico ${ }^{6}$ ou seja, aquilo que, mais tarde, Simmel chamaria de "lei individual".7 E assim como uma obra de arte criada já é arte e representa a arte, Simmel interpretou do mesmo modo suas ideias científicas no "sentido da moderna vida do espírito", como, por exemplo, quando recomendou como algo novo "diluir o sólido, o idêntico a si mesmo, o substancial em função, força e movimento e reconhecer em todo ser o processo histórico de seu devir" (Simmel, I989 [1890]: I30); ou quando acreditou satisfazer a "exigência da cientificidade moderna" com sua "Einleitung in die Moralwissenschaft" [Introdução à ciência moral] (I892-I893), que explicava "a vida ética [...] por meio de sua dissolução psicológica em processos singulares e por meio da dedução histórica dos mesmos"; 8 ou quando falou da "ciência moderna - analisadora e atomizadora" (Simmel, 2004a: 32). ${ }^{9}$

Porém, quando Simmel proclamou o Naturalismo e o Individualismo "como duas tendências essenciais da moderna vida do espírito" (Simmel, 2000 
[I89Ib]: 304), isso remetia primeiramente a seus próprios interesses científicos pela "ciência moderna" da sociologia, que, no espírito do positivismo, era entendida como ciência da experiência, um aspecto sobre o qual Simmel sempre insistia (ver Simmel, I989 [I890]: II6 ss.; I992 [I894]: 58 ss.). Quando Simmel soube que Arno Holz, uma das lideranças do Naturalismo literário (e que durante algum tempo foi também seu vizinho), e seu amigo Paul Ernst, também ele um naturalista, pretendiam escrever uma "Sociologia da arte" como Zola (ver Bertaux \& Bertaux, I98I: 259), pareceu-lhe que seu ponto sociológico central - a saber, a relação quase dialética entre a superação do "modo de concepção individualista" do século XIX e, ao mesmo tempo, o reconhecimento das "forças sociais e dos movimentos coletivos" como "verdadeiramente efetivos e decisivos" (Simmel, I992 [1894]: 52) -, , possibilitava introduzir, como um novo tema na discussão naturalista, uma individualidade condicionada por essas "forças". ${ }^{\text {II }}$ Se, por um lado, o individualismo é superado pelos grupos sociais como o verdadeiro motor da sociedade, então a pressão interna por equalização nesse grupo produz uma nova forma do individualismo. ${ }^{\mathrm{I} 2}$ Isso integrava tematicamente a discussão no Naturalismo estético-literário, que pretendia ver o artista como criador e, ao mesmo tempo, como momento em uma série natural de seleção.

Sob a categoria do "novo", Simmel acreditava poder introduzir em seus interesses científicos questões artístico-filosóficas, estéticas, de crítica social, positivistas, de evolucionismo darwinista, sociológicas e da psicologia dos povos, até então incompatíveis. A partir daí, esses interesses e esse conjunto de questões adequaram-se mutuamente, se transformaram em um buquê, o que gerou um laço entre Simmel e o Naturalismo, do qual ele se ocupou durante toda a vida; até mesmo em seu espólio havia um estudo intitulado "Zum Problem des Naturalismus" [Sobre o problema do Naturalismo] (2004b: 220-248).

Simmel preservou esse buquê de interesses em diferentes disciplinas científicas durante toda a vida, e vemos isto na referência a assuntos mencionados associativamente e não pertencentes ao tema principal em cada um de seus estudos. Teoricamente, podemos justificar isto em Simmel - sempre com Kant em mente - pelo fato de que, para ele, o conhecer parece estar vinculado a "impressões sensíveis", ou seja, pelo fato de que "nosso conhecimento não ultrapassa o círculo do sensorium, da experiência" (Simmel, 2000 [189Ia]: 272). ${ }^{\mathrm{I} 3}$ Consequentemente, as coisas não nos são dadas, mas apenas a sua enunciação, seu fenômeno, o que significa que jamais podemos avançar para a relação entre as coisas, mas sempre permaneceremos dependentes de nossa experiência. Portanto, não há como dizer objetivamente se as coisas são compatíveis ou não. Essa suposição fundamental de Simmel corresponde à sua caracterização por Paul Ernst, que atribuía a Simmel um "ímpeto vivo" 
de logo abandonar o concreto assim que o tocasse, para rapidamente alcançar o abstrato; jamais considerou um fim último a própria experiência, como conhecimento imediato, e nem mesmo os objetos artísticos ele desfrutava durante muito tempo como coisas reais, passando a refletir logo sobre o ato do desfrutar; e quase poderíamos dizer que ele desfrutava dessa reflexão (Ernst, I902: 139). ${ }^{\text {I4 }}$

Simmel usou as palavras "novo" e "moderno" simultaneamente. Se contemplarmos sua obra, percebemos que ele usou "moderno" pela primeira vez no final da década de I880, e no início da década de I890, de forma excessiva, tendo em vista sempre um objeto concreto, a saber, a "moderna visão do mundo", a "moderna visão da vida". A partir dos meados da década de I89o, seu emprego da palavra "moderno" diminuiu, ele se concentrou em uma "cultura moderna" em sentido mais amplo, e em um "moderno estilo de vida" na Filosofia do dinheiro (I900), o que permite supor que essas passagens em que se usa o adjetivo são mais antigas. Nesse momento, e também em outros contextos nos anos seguintes, "moderno" permaneceria semanticamente vinculado a "temporalmente mais recente" e ao "progresso", sendo que, em Simmel, a "modernidade" está sempre referida ao "espírito moderno" ou à "moderna vida do espírito".

A fórmula de desenvolvimento para o que há de moderno no espírito moderno é que ele extrai os elementos vitais de sua unidade originalmente indiferenciada e arraigada, individualizando-os e conscientizando-se deles, para somente então, após essa formação especializada, reuni-los em uma nova unidade. Quando isto fracassa, permanece a ruptura caracteristicamente moderna, a especialização exacerbada dos conteúdos individuais da existência. (Simmel, 1995 [1902]: 98)

Diante da conotação positiva do conceito, a palavra "moderno" desapareceu quase que completamente das publicações de Simmel, mas também de suas cartas pessoais durante os anos de guerra entre I9I4 e I9I8, e, quando mesmo assim ele a usou, o período do "moderno" ampliou-se para décadas, até mesmo séculos, provavelmente para tornar palpáveis as falhas do presente de então.

Assim, o adjetivo "moderno" - na crítica do novo contraposto à permanência de uma cultura do ontem tornada contingente - adquire um ar de esperança de que as conquistas culturais não se percam após a guerra. A semântica de "moderno" no uso do Simmel tardio conota, assim, surpreendentemente o uso da "modernidade" vivenciada pelo Simmel jovem. Na época, entre I888 e I894, a "modernidade" havia sido uma experiência concreta para Simmel, pois ela representava os anseios do movimento naturalista. Simmel abordou suas condições e tendências numa resenha, em tom acusador e veemente, da obra de Rudolf Eucken, Lebensanschauungen der grossen Denker [Visões da vida dos grandes pensadores] (2000 [I89Ia]), condenando a ignorância em relação ao Naturalismo e ao movimento de protesto social, assim como o equívoco de suas avaliações, e criticando duramente todos os 
seus respectivos posicionamentos. ${ }^{15}$ Dez das trinta páginas da resenha são reservadas à defesa do credo do movimento naturalista. ${ }^{16}$ Se aqui ainda encontramos um Simmel engajado, seu entusiasmo esfriou rapidamente com o fim do movimento naturalista entre I894-I895 e o termo "moderno" passou a ser vinculado cada vez mais - e agora mais distanciado e objetivo - à arte. O fim do movimento naturalista não ocorreu por causa do fracasso na realização de suas metas - até porque, do ponto de vista atual, há muitas indicações de que seu impacto na área artística foi fundamental e duradouro, mas principalmente porque as circunstâncias políticas e sociais se transformaram repentinamente. No caso da Alemanha, devemos lembrar a virada conservadora na política do imperador Guilherme II, que se manifestou no "projeto de lei do golpe" contra a social-democracia, apesar de rejeitada pelo Reichstag (1894/95); como também a "Era Stumm", que começou no início de I895, e que mobilizou forças contra as reformas sociais e contra as tendências liberais e socialistas nas universidades e na cena artística. Com relação à França, lembramos um desenvolvimento semelhante do movimento antiparlamentar e nacionalista de George Boulanger no final da década de i88o e o caso Dreyfus, iniciado em I894. Tudo isso aconteceu no contexto do final da "Great Depression" (Rosenberg, 1967). Sobre esta fase, em I894 o jurista Rudolf von Gneist afirmou com perspicácia que, na Europa central do início da década de i89o, todos reclamavam uma situação de emergência, que contudo não podia ser remetida a uma situação de emergência econômica, mas, antes, resultava "de um 'sentimento de insegurança' diante das transformações econômicas, políticas e sociais" (apud Mommsen, I969: 46). Um sentimento coletivo de impotência diante de potências anônimas fomentou uma sensibilidade de crise e sufocou a crença na naturalidade do progresso econômico, que, na época, ainda era sempre entendido como progresso social. Uma súbita perda de futuro marcou a vida do espírito. E isto tornou obsoletos os aspectos da "modernidade" que apontavam para o futuro.

Em I89ı, Simmel havia chamado ainda a atenção de Eucken para o fato de que a modernidade estava redefinindo "os conceitos fundamentais do ser humano e do mundo prático". O ser humano não era valioso como "membro da sociedade burguesa", nem como

ser natural romanticamente idealizado [...], mas como ser racional ético; a dimensão prática, porém, significa não a realização de fins no âmbito do mundo da experiência, mas a criação de um novo mundo (Simmel, 2000 [1891a]: 273).17

A "criação de um novo mundo" que, em I89I, era ainda uma fonte de inspiração, alguns anos depois já soava antiquada e mesmo constrangedora. Simmel deve ter vivenciado algo semelhante com relação ao adjetivo "moderno". Em vez de "moderna", a poesia de Stefan Georges tornou-se, para ele, a partir de certo momento, "do presente", e ele a louvou como "auge do anti- 
naturalismo" (Simmel, I992 [I898]: 294), e "presente" se tornou para ele também a cultura na virada do século. ${ }^{18}$ Mas existe uma exceção: Rodin, que é para Simmel o artista da modernidade em si. Em todos os quatro trabalhos sobre Rodin, Simmel faz um uso excessivo da palavra "moderno" e problematiza o Naturalismo. Ele atribuiu a Rodin, que se apresentava "com paixão como "naturalista'" (Simmel, 2000 [I9I7]: 309) uma "lei individual" para as concepções altamente subjetivas segundo as quais ele dava forma às suas estátuas (Simmel, I995 [1902]: 93). Simmel falou sobre a ascensão e a queda do movimento naturalista (Simmel, I995 [1902]: 96-98), e aqui encontramos também a muito conhecida e única circunscrição de "modernidade":

Pois a essência da modernidade é o psicologismo, o vivenciar e interpretar o mundo segundo as reações do nosso interior e, na verdade, como um mundo interior, a dissolução dos conteúdos fixos no elemento fluido da alma, da qual toda substância foi extraída e cujas formas são todas apenas formas de movimentos (Simmel, 200 I [I909]: 34 ss.). ${ }^{\text {I9 }}$

A essência (ou seja, a essência daquelas qualidades, relações e regularidades, a partir da qual os processos complexos e especiais do objeto são explicáveis) da modernidade é o psicologismo (isto é, um fenômeno que deve ser remetido a vivências psíquicas, processos e formações psicológicas), que condensa a vivência e a valoração da reconfiguração do mundo da vida cunhado pelo capitalismo de acordo com "a direção da moderna vida do espírito" em uma imagem do mundo. Em I89o, ele concretizou essa direção como:

diluir o que é fixo, idêntico a si mesmo, substancial em função, força e movimento e reconhecer em todo ser o processo histórico de seu devir (Simmel, I989 [1890]: I30).

Esta a circunscrição que Simmel manteve pelo menos até o início da Primeira Guerra Mundial, quando escreveu, por exemplo, em igı ou I9ı I:

A dissolução histórico-temporal de tudo o que é substancial, absoluto, eterno no fluxo das coisas, na transformação histórica, na realidade apenas psicológica me parece a salvo de um subjetivismo e ceticismo insustentáveis apenas se substituirmos aqueles valores substancialmente fixos pela interação viva de elementos, que também estão sujeitos à mesma dissolução no infinito. (Simmel, 2004c: 304)

Falta aqui o aspecto do psicologismo que conduz ao relativismo, mas permanecem centrais as diretrizes fundamentais devidas ao mecanicismo e ao darwinismo, de forma que podemos partir do pressuposto de que a explicação sobre a "essência da modernidade", formulada em I902, poderia ter sido escrita já dez anos antes, na sua época do movimento naturalista. E isto nada tem de surpreendente, pois o declínio do movimento não anulou todas as mudanças sociais, de forma que a "modernidade" continuou a existir pelo menos no domínio da cultura, mesmo que apenas como "falsa consciência", como se poderia dizer, pois o "ser" respectivo se perdeu de vista, e um mal- estar psíquico permaneceu até o início da Primeira Guerra Mundial: o que 
Simmel também percebeu e verbalizou, quando, em I9I4, escreveu que "há uma série de anos" surgiram na Alemanha pequenos "movimentos espirituais" que, "mais ou menos conscientemente", defendiam "o ideal de um novo homem" (Simmel, 2003 [I9I4]: 282).

A concepção de modernidade de Simmel se desdobrou nas suas elaborações sobre o estilo de vida, na sua fixação em objetos e, por fim, na estetização.

Simmel organizara sua Filosofia do dinheiro (I900) de tal forma que a parte analítica seguia-se - de forma bem kantiana - de uma parte sintética, que o levava ao último capítulo intitulado "Estilo da vida". Principalmente a partir da década de I980, esta expressão fez carreira na sociologia, e incorporou-se também à filosofia, à psicologia, à crítica da cultura e à estatística, e, neste movimento, seu criador foi esquecido. Simmel, porém, usou-a apenas durante pouco tempo, o que nos leva a supor que, para ele, o conceito e o problema se tornaram inadequados, seja porque ele veio a ver o problema de outra forma, seja porque o conceito se tornou rígido demais. Com "estilo de vida", Simmel pretendia referir-se à relação, em uma comunidade, "na qual a cultura tornada objetiva se relaciona à cultura dos sujeitos" (Simmel, I989 [1900]: 628)..$^{20}$ Num sentido mais estrito, porém, a expressão visava o moderno estilo de vida dos habitantes das cidades grandes do final do século XIX, caracterizado pelo fato de que os "aparelhos, meios de transporte, produtos da ciência, da técnica, da arte [são] indizivelmente cultivados", ao passo que a "cultura dos indivíduos [...] de forma alguma avançou na mesma medida, e em muitos casos até regrediu" (Simmel, I989 [1900]: 620). Porém, quando Simmel toma de empréstimo o conceito de "estilo" da história da arte ou, mais provavelmente, da filosofia, ele está ciente da ambivalência do antigo conceito, quando "estilo" significava, por um lado, o revestimento de um conteúdo (exornatio), e, por outro, a encarnação de um conteúdo (incarnatio). Simmel reuniu ambos os significados em seu conceito de "estilo de vida", na medida em que torna as transformações da cultura objetiva em problema para o indivíduo, às quais este só pode responder de acordo com parâmetros fisiológicos. Consequentemente, o conceito do "estilo de vida" em Simmel não é um conceito estratificador - como, por exemplo, em Bourdieu -, mas, sim, um conceito epocal, pois se aquele se refere a uma "diferenciação sincrônica", este a uma "diferenciação diacrônica", tal como Simmel fixou conceitualmente em seu livro Über sociale Differenzierung [Sobre a diferenciação social] (I989 [1890]: 289 ss.).

Simmel via o "fundamento" do "tipo de individualidades das grandes cidades" na "intensificação da vida nervosa" (Simmel, I995 [I903]: II6), que ora pode levar à hiperestesia, ora à anestesia (Simmel, 2005 [I890]: 246). ${ }^{21}$ A "inquietação confusa, que se manifesta seja como o tumulto da cidade grande, seja como a mania de viagens, seja como a caça selvagem da concor- 
rência, ou como a infidelidade especificamente moderna nos terrenos do gosto, dos estilos, das convicções, dos relacionamentos", é aparentemente típica da vida nas cidades grandes. Não é, porém, causada pelo moderno estilo de vida, senão que é, antes, uma "descarga" daquele "sentimento abafado de tensão", daquela "inquietação secreta", daquele "ímpeto desorientado sob o limiar da consciência", que, no habitante da cidade grande, se acumula reativamente no transbordamento de estímulos (Simmel, I989 [1900]: 674 Ss.).

A divisão de trabalho, que anda de mãos dadas com o sistema monetário, condiciona aquelas transformações sociais que, como cultura objetiva, oferece aos indivíduos a possibilidade de ser utilizada, o que se manifesta no moderno estilo de vida.

Na medida em que todo o conteúdo objetivo da vida se torna cada vez mais objetivo e impessoal, para que o resto, que não pode ser objetivado, se torne cada vez mais pessoal, algo incontestavelmente próprio do eu. (Simmel, I989 [1900]: 652)

Se essas transformações estão, em geral, em um relação recíproca com as características do ser humano moderno, então não só a calculabilidade e a racionalidade são determinadas pelo dinheiro (ver Simmel, I992 [I896b]: I92), mas também a distância, o ritmo e a velocidade ${ }^{22}$ (introduzidos na sociologia como semicategorias) que operacionalizam o estilo de vida entre as culturas objetiva e subjetiva.

$\mathrm{Na}$ época, isto era tão novo para a sociologia e para a filosofia que somente cem anos depois, com certa relutância, nos dispusemos a seguir Simmel. Novo foi também o método por ele escolhido; pois, como Simmel explicou, a filosofia, cujo problema era "a totalidade da existência", costumava se estreitar diante dessa grandeza e dar menos do que ela parecia estar obrigada a dar. Em oposição a isto, Simmel, na Filosofia do dinheiro, partiu conscientemente de um objeto limitado e pequeno, para "fazer jus a ele" por meio de sua ampliação e "condução para a totalidade e o mais universal". Com isto, ele pretendia aproveitar a possibilidade de "encontrar em cada singularidade da vida a totalidade de seu sentido" (Simmel, I989 [I900]: I2 ss.)

Este procedimento metodológico encontra justificativa no Naturalismo, pois este romperia o "casual" e concederia a "cada ponto do ser o mesmo direito" (Simmel, I992 [1896a]: I99; ver também Simmel, I992 [1899]: 409). Não se trata de um método indutivo, a coisa singular como tal não representa o todo. Para Simmel, este método é moderno e aponta para o futuro, pois pretende, a partir do "singular imediato, do simplesmente dado, lançar uma sonda até a camada dos significados últimos do espírito" (Simmel, 2003 [I916]: 309; ver também I995 [I903]: I20). Para passar da parte ao todo de modo justificado não é necessário determinar a significância e a validade, dado que tudo está em ligação com tudo (interação). Para Simmel, cada "partícula do mundo é igualmente significante" (Simmel, 2000 [1898]: 409) e a sonda pode ser lançada nas profundezas a partir de qualquer uma delas. 
Simmel empregou esse método em sua Filosofia do dinheiro, "como primeira tentativa de expor em um símbolo o desenvolvimento de toda a cultura anímica da humanidade", tal como ele formulou pouco antes de sua morte, quando fez o balanço de sua própria "individualidade espiritual". Essa sua tentativa teria sido algo "absolutamente novo". A abordagem moderna do livro "não foi, até agora, reconhecida nem aplicada de forma produtiva" (Simmel, 20I5 [I9I8]: 72) - e tem permanecido assim até hoje.

Nesse método se firmam duas características intimamente interligadas do restante de sua obra: como sociólogo de primeira hora, ele foi capaz de partir de coisas - da asa do jarro, da moldura, da ruína, do adorno, da ponte, da porta, da cadeira etc. -, a ponto de ser celebrado como inventor da "sociologia das coisas"; e na década de 1890 ele encontrou no ensaio o gênero de texto mais apropriado a seu pensamento, tornando-se o "criador do ensaio filosófico" (Mathias, I928: 194).

Ainda em vida, Simmel foi acusado de ter publicado textos sobre - possivelmente - muitos assuntos e - possivelmente - em muitos lugares, de modo que restaria indagar como todos os aspectos emaranhados de seu pensamento se harmonizam uns com os outros. Uma pergunta que certamente ele também fez a si mesmo e que acreditou, ao final de sua vida, poder responder: todos os seus trabalhos, diz ele, formavam, no fundo, um conjunto:

nascidos de uma nostalgia metafísica, que se exprime igualmente na relação ansiada entre a parte e o todo, entre a superfície e a profundidade, entre realidade e ideia. (Simmel, 20I5 [I9I6]: 7I)

Recebido em I2/I2/20I4 | Aprovado em Io/02/2015

Otthein Rammstedt, nascido em I938, é professor aposentado de Sociologia e Filosofia Social na Universidade de Bielefeld, Alemanha, editor da Georg Simmel Gesamtausgabe (GSG) e presidente da Georg Simmel Society. 


\section{NOTAS}

I Optamos por manter sempre a indicação da publicação original junto àquela da Georg Simmel Gesamtausgabe a fim de especificar os textos de anos diferentes incluídos em um mesmo volume desta e também como forma de preservar a desenvoltura e destreza com que o autor se move entre essas referências. [N.E.]

2 O termo foi, supostamente, cunhado por Eugen Wolff (apud Schutte \& Sprengel, 1987: 13).

3 Ver, também, as posições aterrorizadas de Theobald Ziegler (I9I I [1899]: 664 Ss.), que critica a falta de moral, a juvenilidade e a falta de medida na crítica e nas reivindicações do "Jugendbewegung" [Movimento da juventude].

4 Essa declaração de Simmel corresponde ao que hoje chamamos de "Naturalismo ontológico"; já que, nesse programa, o problema na "entidade natural" não pode ser solucionado, essa abordagem é hoje substituída pelo "Naturalismo metodológico", segundo o qual tudo que ocorre é evento natural, contanto que possa "ser descrito e explicado completamente" pelas ciências naturais, "sobretudo também a ação humana e os artefatos culturais" (ver Hartmann \& Lange, 2000: 147).

5 Simmel se referiu a isso na introdução a "Philosophischen Kultur: Gesammelte Essais" [Cultura Filosófica: Ensaios Reunidos] (I996 [I9IIa]: I62) como "determinada atitude diante do mundo e da vida, uma forma e um modo funcionais de absorver as coisas e de proceder interiormente com elas". Sobre a dificuldade de expressar isto em alemão, ver também o termo "Lebensgefühl" em Friedrich Nietzsche, situado no mesmo domínio semântico. Ver Nietzsche (I972 [1878-1879]: 877).

6 Essa ideia é desdobrada nos seguintes trabalhos de Simmel: "L'art pour l'art" (2003 [I9I4]); "Philosophie der Kunst" [Filosofia da Arte] (20Io [I9I3-I9I4]), na seção "Über den Naturalismus in der Kunst" [Sobre o Naturalismo na arte]; e "Zum Problem des Naturalismus" [Sobre o problema do Naturalismo] (2004a: p. 220-238).

7 Simmel emprega o termo pela primeira vez provavelmente em I902. Ele então desenvolveu sua ideia em: "Das individuelle Gesetz. Ein Versuch über das Prinzip der Ethik" 
[A lei individual. Um ensaio sobre o princípio da ética] (200I [I9I3]) e como último capítulo em sua última monografia, "Lebensanschauung" [Visão da vida] (I999 [I9I8]: 346-425).

8 Carta de Simmel a Wilhelm Hertz de i8 de dezembro de I89I (Simmel, 2008: 56); Simmel (I989 [I892]: II2).

9 Ver a declaração correspondente em Simmel (I989 [I890]: I 28 ss.).

Io Lá, ele ressalta explicitamente: "Nenhum objeto das ciências do espírito pode se esquivar dessa virada; mesmo onde os movimentos se expressam de forma tão individual como, por exemplo, na realização artística, procuramos na evolução do gênero as causas a partir das quais as sensações do belo surgiram" etc.

II Este é um fenômeno problematizado repetidas vezes por Simmel: pela primeira vez, no estudo "Bemerkungen zu socialethischen Problemen" [Comentários sobre problemas ético-sociais] (ver I989 [1888]: 20-28); depois como $3^{\circ}$ capítulo: "Die Ausdehnung der Gruppe und die Ausbildung der Individualität" [A expansão do grupo e a formação da individualidade] (ver I989 [I890]: I69-I98); retomado no I0 ${ }^{\circ}$ capítulo: "Die Erweiterung der Gruppe und die Ausbildung der Individualität" [A ampliação do grupo e a formação da individualidade] (ver I992 [I908]: 79I-863).

I2 Desenvolvido tematicamente por Simmel pela primeira vez em "Die beiden Formen des Individualismus" [As duas formas do individualismo] (I995 [I90I]).

I3 O pensamento kantiano se encontra em "Metaphysische Anfangsgründe der Naturwissenschaft" [Princípios metafísicos da ciência da natureza] (I786), onde lemos: "A natureza em seu sentido material, não como constituição, mas como essência de todas as coisas, contanto que possam ser objetos de nossos sentidos, portanto, também da experiência, ou seja, o todo de todos os fenômenos, i.e., do mundo dos sentidos, com exclusão de todos os objetos não sensíveis" (A III).

I4 A isso corresponde a lembrança de Friedrich Meinecke (I949: I02 ss.), segundo a qual, ao oferecer a Simmel uma cadeira, "ele permaneceu de pé e começou a elaborar uma filosofia da cadeira e do ato de oferecer uma cadeira". 
I5 Permanece em aberto se Simmel, ao escolher o título de seu último livro, Lebensanschauung [Visão da vida], pensou ainda no título do livro de Eucken optando conscientemente pelo singular, pois não existe documento que forneça uma resposta para essa pergunta.

I6 O páthos aqui celebrado por Simmel era próprio do movimento. Ver a primeira proclamação relevante do movimento naturalista em Berlim: Hermann Conradi, "Unser Credo" [Nosso credo] [1884] (apud Schutte \& Sprengel, I98I: I8I-I86).

I7 Nesse mesmo sentido, Simmel escreve ainda em I893: "Uma das tarefas mais elevadas da humanidade é substituir velhos ideais, esperanças e necessidades da alma no momento certo por novos. O nosso tempo alcançou um destes pontos de virada, em que os valores da vida, os interesses do coração, os anseios e vislumbres, que satisfaziam em tempos passados, hoje empalidecem, e em que se evidencia se realmente possuímos a força para transpor de forma enérgica os nossos ideais para os interesses sociais, que representam a estrela guia do futuro" (Liesegang, 2005 [1892]: 282 ss.).

I8 Assim em todo o seu ensaio "Persönliche und sachliche Kultur" [Cultura subjetiva e objetiva] (I992 [1900]).

I9 Este ensaio de Simmel foi incluído na versão ampliada de: "Rodin" (com uma observação preliminar sobre Meunier), publicado em "Philosophische Kultur. Gesammelte Essais" [Cultura filosófica. Ensaios reunidos] (I996 [I9IIb]). A passagem aqui citada se encontra na p. 346.

20 A Filosofia do dinheiro foi publicada inicialmente em I900; a segunda edição, de I907, também citada no texto original de Rammstedt, contem algumas alterações pontuais, que não alteram nem a estrutura, nem o argumento do livro. [N. E.]

2 I Em sua "Soziologischen Aesthetik" [Estética sociológica] (I992 [I896a]: 2I4) ele fala nesse contexto de "neurastenia".

22 Não se sabe se Simmel adotou as características da teoria da música ou de Nietzsche ou até mesmo de Spencer. 


\section{REFERÊNCIAS BIBLIOGRÁFICAS}

Bertaux, Félix \& Bertaux, Pierre. (I98I). Berlin I880 bis I89o - Hauptstadt des Naturalismus. In: Kühn, Hellmut (org.). Preußen, Dein Spree-Athen. Beiträge zu Literatur, Theater und Musik in Berlin. (Catálogo da exposição "Preußen - Versuch einer Bilanz", vol. 4). Reinbek: Rowohlt, p. 250-264.

Ernst, Paul. (I958 [1902]). Erinnerungen an Simmel. In: Gassen, Kurt \& Landmann, Michael (orgs.). Buch des Dankes an Georg Simmel. Briefe, Erinnerungen, Bibliographie. $\mathrm{Zu}$ seinem I00. Geburtstag am I. März I958. Berlim: Duncker \& Humblot, p. I39-I42.

Hartmann, Dirk \& Lange, Rainer. (2000). Ist der erkenntnistheoretische Naturalismus gescheitert? In: Keil, Geert \& Schnädelbach, Herbert (orgs.). Naturalismus. Philosophische Beiträge. Frankfurt am Main: Suhrkamp, p. I44-I62.

Landmann, Edith. (1958). Erinnerungen an Simmel. In: Gassen, Kurt \& Landmann, Michael (orgs.). Buch des Dankes an Georg Simmel. Briefe, Erinnerungen, Bibliographie. Zu seinem I00. Geburtstag am I. März I958. Berlim: Duncker \& Humblot, p. 208-2II.

Lange, Annemarie. (1984). Berlin zur Zeit Bebels und Bismarcks zwischen Reichsgründung und Jahrhundertwende. Berlim: Dietz.

Liesegang, Paul. (2005 [1892]). Etwas vom Spiritismus. In: Köhnke, Klaus Christian (org.). Georg Simmel Gesamtausgabe, vol. I7. Frankfurt am Main: Suhrkamp, p. 274-283.

Mauthner, Fritz. (I9I8). Georg Simmel: Geboren I März I858, gestorben 26 September I9I8. Vossische Zeitung, I8 de outubro.

Matthias, Leo. (1958 [1928]). Erinnerungen an Simmel. In: Gassen, Kurt \& Landmann, Michael (orgs.). Buch des Dankes an Georg Simmel. Briefe, Erinnerungen, Bibliographie. $\mathrm{Zu}$ seinem I00. Geburtstag am I. März I958. Berlim: Duncker \& Humblot, p. I92-I94.

Meinecke. Friedrich. (1949). Strasburg, Freiburg, Berlim I90II9I9. Erinnerungen. Stuttgart: Koehler.

Mommsen, Wolfgang J. (org.). (I969). Das Zeitalter des Imperialismus. Frankfurt am Main: Fischer. 
Nietzsche, Friedrich. (1972 [1878-1879]). Menschliches, Allzumenschliches. Ein Buch für freie Geister. Organizado por Karl Schlechta. Obra em seis volumes. Frankfurt am Main: Ullstein Verl (vol. 2).

Rosenberg, Hans. (1967). Große Depression und Bismarkzeit. Wirtschaftsablauf, Gesellschaft und Politik in Mitteleuropa. Berlim: de Gruyter.

Scheu, Robert. (1898). Kinder des Positivismus. Die Zeit, Viena, 20I, 6 agosto, p. 92 ss.

Schutte, Jürgen \& Sprengel, Peter (orgs.). (1987). Die Berliner Moderne I885-I9I4. Stuttgart: Reclam.

Simmel, Georg. (2015 [I9I8]). Unzweideutiges Bild meiner geistigen Individualität. In: Rammstedt, Otthein (orgs.). Georg Simmel Gesamtausgabe, vol. 24. Frankfurt am Main: Suhrkamp, no prelo.

Simmel, Georg. (2015 [1916]). Wenn ich Bilanz ziehe... In: Rammstedt, Otthein (orgs.). Georg Simmel Gesamtausgabe, vol. 24. Frankfurt am Main: Suhrkamp, no prelo.

Simmel, Georg. (2010 [I9I3-I9I4]). Philosophie der Kunst. In: Rammstedt, Angela \& Rol, Cécile (orgs.). Georg Simmel Gesamtausgabe, vol. 2I. Frankfurt am Main: Suhrkamp, p. I77-I97.

Simmel, Georg. (2010 [1902]). Tendencies in German life and thought since I870. In: Frisby, David (org.). Georg Simmel Gesamtausgabe, vol. I8: Englischsprachige Veröffentlichungen I893-ı9ıo. Retradução para o alemão pelo autor. Frankfurt am Main: Suhrkamp, p. 167-202.

Simmel, Georg. (2008 [I89I]). Carta de Georg Simmel a Wilhelm Hertz (Bessersche Buchhandlung) de i8 de dezembro. In: Köhnke, Klaus Christian (org.). Georg Simmel Gesamtausgabe, vol. 22: Briefe I880-I9I I. Frankfurt am Main: Suhrkamp, p. 56.

Simmel, Georg. (2005 [1900]). Momentbilder sub specie aeternitatis: Kein Dichter. In: Köhnke, Klaus Christian (org.). Georg Simmel Gesamtausgabe, vol. I7. Frankfurt am Main: Suhrkamp, p. 400-402.

Simmel, Georg. (2005 [1893]). Gerhart Hauptmanns "Weber". In: Köhnke, Klaus Christian (org.). Georg Simmel Gesamtausgabe, vol. I7. Frankfurt am Main: Suhrkamp, p. 26-28. 
Simmel, Georg. (2005 [1890]). Ueber Kunstausstellungen. In: Köhnke, Klaus Christian (org.). Georg Simmel Gesamtausgabe, vol. I7. Frankfurt am Main: Suhrkamp, p. 242-250. Simmel, Georg. (2004a [Póstumo]). Allgemeine Einleitung: Werte des Goetheschen Lebens. In: Karlsruhen, Torge \& Rammstedt, Otthein, Rammstedt (org.). Georg Simmel Gesamtausgabe, vol. 20. Frankfurt am Main: Suhrkamp, p. II-79.

Simmel, Georg. (2004b [Póstumo]). Zum Problem des Naturalismus. In: Karlsruhen, Torge \& Rammstedt, Otthein, Rammstedt (org.). Georg Simmel Gesamtausgabe, vol. 20. Frankfurt am Main: Suhrkamp, p. 220-248.

Simmel, Georg. (2004C [Póstumo, circa I9Io]). Fragment einer Einleitung. In: Karlsruhen, Torge \& Rammstedt, Otthein, Rammstedt (org.). Georg Simmel Gesamtausgabe, vol. 20. Frankfurt am Main: Suhrkamp, p. 304-305.

Simmel, Georg. (2003 [1916]). Rembrandt. Ein kunstphilosophischer Versuch. In: Kösser, Uta; Kruckis, Hans-Martin \& Rammstedt, Otthein (orgs.). Georg Simmel Gesamtausgabe, vol. I5. Frankfurt am Main: Suhrkamp, p. 305-515.

Simmel, Georg. (2003 [I9I4]). Deutschlands innere Wandlung. In: Kösser, Uta; Kruckis, Hans-Martin \& Rammstedt, Otthein (orgs.). Georg Simmel Gesamtausgabe, vol. I5. Frankfurt am Main: Suhrkamp, p. 27I-285.

Simmel, Georg. (200I [19I3]). Das individuelle Gesetz. Ein Versuch über das Prinzip der Ethik. In: Kramme, Rüdiger \& Rammstedt, Angela (orgs.). Georg Simmel Gesamtausgabe, vol. I2. Frankfurt am Main: Suhrkamp, p. 4I7-470.

Simmel, Georg. (200I [1909]). Die Kunst Rodins und das Bewegungsmotiv in der Plastik. In: Kramme, Rüdiger \& Rammstedt, Angela (orgs.). Georg Simmel Gesamtausgabe, vol. I2. Frankfurt am Main: Suhrkamp, p. 28-36.

Simmel, Georg. (2000). Gesamtausgabe, vol. I: Das Wesen der Materie nach Kant's Physischer Monadologie. Abhandlungen I882-I884. Rezensionen I883-I90I. Organizado por Klaus Christian Köhnke. Frankfurt am Main: Suhrkamp.

Simmel, Georg. (2000 [I9I7]). Erinnerung an Rodin. In: Latzel, Klaus (org.). Georg Simmel Gesamtausgabe, vol. I3 Frankfurt am Main: Suhrkamp, p. 307-320. 
Simmel, Georg. (2000 [I9I4]). L'art pour l'art. In: Latzel, Klaus (org.). Georg Simmel Gesamtausgabe, vol. I3. Frankfurt am Main: Suhrkamp, p. 9-I5.

Simmel, Georg. (2000 [1898]). Resenha de "Polymeter", de P. Ernst. In: Köhnke, Klaus Christian (org.). Georg Simmel Gesamtausgabe, vol. I. Frankfurt am Main: Suhrkamp, p. 409-4I8.

Simmel, Georg. (2000 [I89ra]). Resenha de "Lebensanschauungen", de Rudolf Eucken. In: Köhnke, Klaus Christian (org.). Georg Simmel Gesamtausgabe, vol. I. Frankfurt am Main: Suhrkamp, p. 25I-280.

Simmel, Georg. (2000 [189Ib]). Resenha de "Das Problem der Ethik in der Gegenwart", de Hans Gallwitz. In: Köhnke, Klaus Christian (org.). Georg Simmel Gesamtausgabe, vol. I. Frankfurt am Main: Suhrkamp, p. 304-305.

Simmel, Georg. (2000 [I890]). Rembrandt als Erzieher. Resenha de "Rembrandt als Erzieher. Von einem Deutschen" (Leipzig, I89o), de Anônimo [i.e. August Julius Langbehn]. In: In: Köhnke, Klaus Christian (org.). Georg Simmel Gesamtausgabe, vol. I. Frankfurt am Main: Suhrkamp, p. 232-243. Simmel, Georg. (I999 [I9I8]). Lebensanschauung. In: Fitzi, Gregor \& Rammstedt, Otthein (orgs.). Georg Simmel Gesamtausgabe, vol. I6. Frankfurt am Main: Suhrkamp, p. 209-425.

Simmel, Georg. (I996 [Igria]). Philosophischen Kultur: Gesammelte Essais. Kramme, Rüdiger \& Rammstedt, Otthein (orgs.). Georg Simmel Gesamtausgabe, vol. I4. Frankfurt am Main: Suhrkamp, p. I59-459.

Simmel, Georg. (I996 [I9IIb]). Philosophische Kultur. Gesammelte Essais. Kramme, Rüdiger \& Rammstedt, Otthein (orgs.). Georg Simmel Gesamtausgabe, vol. I4. Frankfurt am Main: Suhrkamp, p. 330-348.

Simmel, Georg. (1995). Gesamtausgabe, vol. 7: Aufsätze und Abhandlungen I90I-I908. Band I. Organizado por Rüdiger Kramme, Angela Rammstedt e Otthein Rammstedt. Frankfurt am Main: Suhrkamp.

Simmel, Georg. (I995 [1903]). Die Großstädte und das Geistesleben. In: Kramme, Rüdiger; Rammstedt, Angela \& Rammstedt, Otthein (orgs.). Georg Simmel Gesamtausgabe, vol. 7. Frankfurt am Main: Suhrkamp, p. II6-г3I. 
Simmel, Georg. (I995 [1902]). Rodins Plastik und die Geistesrichtung der Gegenwart. In: Kramme, Rüdiger; Rammstedt, Angela \& Rammstedt, Otthein (orgs.). Georg Simmel Gesamtausgabe, vol. 7. Frankfurt am Main: Suhrkamp, p. 92-ıоo.

Simmel, Georg. (I995 [I90I]). Die beiden Formen des Individualismus. In: Kramme, Rüdiger; Rammstedt, Angela \& Rammstedt, Otthein (orgs.). Georg Simmel Gesamtausgabe, vol. 7. Frankfurt am Main: Suhrkamp, p. 49-56.

Simmel, Georg. (I992 [1908]). Untersuchung über die formen der Vergesellschaftung. In: Rammstedt, Otthein (org.). Georg Simmel Gesamtausgabe, vol. I I. Frankfurt am Main: Suhrkamp, p. 791-863.

Simmel, Georg. (I992 [I900]). Persönliche und sachliche Kultur. In: Dahme, Heinz-Jürgen \& Frisby, David P. (org.). Georg Simmel Gesamtausgabe, vol. 5. Frankfurt am Main: Suhrkamp, p. 560-582.

Simmel, Georg. (I992 [I899]). Zur Psychologie und Soziologie der Lüge. In: Dahme, Heinz-Jürgen \& Frisby, David P. (org.). Georg Simmel Gesamtausgabe, vol. 5. Frankfurt am Main: Suhrkamp, p. 406-4I9.

Simmel, Georg. (I992 [1898]). Stefan George. Eine kunstphilosophische Betrachtung. In: Dahme, Heinz-Jürgen \& Frisby, David P. (org.). Georg Simmel Gesamtausgabe, vol. 5. Frankfurt am Main: Suhrkamp, p. 287-300.

Simmel, Georg. (I992 [I896a]). Soziologischen Aesthetik. In: Dahme, Heinz-Jürgen \& Frisby, David P. (org.). Georg Simmel Gesamtausgabe, vol. 5. Frankfurt am Main: Suhrkamp, p. I97-2I4.

Simmel, Georg. (I992 [1896b]). Das Geld in der modernen Kultur. In: Dahme, Heinz-Jürgen \& Frisby, David P. (org.). Georg Simmel Gesamtausgabe, vol. 5. Frankfurt am Main: Suhrkamp, p.i78-ıg6.

Simmel, Georg. (I992 [1894]). Das Problem der Sociologie. In: Dahme, Heinz-Jürgen \& Frisby, David P. (org.). Georg Simmel Gesamtausgabe, vol. 5. Frankfurt am Main: Suhrkamp, p. 52-6I.

Simmel, Georg. (I989a). Gesamtausgabe, vol. 2: Aufsätze I887 bis I890. Über sociale Differenzierung (I890). Die Probleme der 
Geschichtsphilosophie (I892). Organizado por Heinz-Jürgen Dahme. Frankfurt am Main: Suhrkamp.

Simmel, Georg. (1989b). Gesamtausgabe, vol. 3: Einleitung in die Moralwissenschaft. Eine Kritik der ethischen Grundbegriffe. Erster Band. Organizado por Klaus Christian Köhnke. Frankfurt am Main: Suhrkamp.

Simmel, Georg. (I989 [I900]). Philosophie des Geldes. In: Frisby, David P. \& Köhnke, Klaus Christian (orgs.). Georg Simmel Gesamtausgabe, vol. 6: Philosophie des Geldes. Frankfurt am Main: Suhrkamp.

Simmel, Georg. (I989 [1892]). Einleitung in die Moralwissenschaft: Eine Kritik der ethischen Grundbegriffe. In: Köhnke, Klaus Christian (org.) Georg Simmel Gesamtausgabe, vol. 3. Frankfurt am Main: Suhrkamp, p. II2 (vol. I).

Simmel, Georg. (I989 [I890]). Über sociale Differenzierung. Sociologische und psychologische Untersuchungen. In: Dahme, Heinz-Jürgen (org.). Georg Simmel Gesamtausgabe, vol. 2. Frankfurt am Main: Suhrkamp, p. Io9-296.

Simmel, Georg. (I989 [I888]). Bemerkungen zu socialethischen Problemen. In: Dahme, Heinz-Jürgen (org.). Georg Simmel Gesamtausgabe, vol. 2. Frankfurt am Main: Suhrkamp, p. 20-36.

Ziegler, Theobald. (I9II [I899]). Die geistigen und sozialen Strömungen des neunzehnten Jahrhunderts. IO-I4 Tausend.

Berlim: Georg Bondi. 
Palavras-chave

Simmel;

Modernidade;

Naturalismo;

Sociologia;

Filosofia

Keywords

Simmel;

Modernity;

Naturalism;

Sociology:

Philosophy.
COMO GEORG SIMMEL CHEGOU À

\section{MODERNIDADE E LHE PERMANECEU FIEL?}

Resumo

Como Georg Simmel, o "primeiro sociólogo da modernidade" segundo David Frisby, teve contato e concebeu a modernidade? Acreditamos que isso tenha ocorrido durante a fase em que o autor participou do Naturalismo - um movimento social que teve forte impacto sobre a sociedade e a cultura alemãs. Argumentamos que Simmel foi fortemente influenciado pelo Naturalismo, pois muitos aspectos de suas ideias teóricas e metodológicas dependem diretamente do conceito de modernidade no sentido atribuído pelo Naturalismo.

\section{HOW DID GEORG SIMMEL CONCEIVE} AND EXPERIENCE MODERNITY AND REMAIN FAITHFUL TO IT?

Abstract

How did Georg Simmel, the "first sociologist of modernity" according to David Frisby, get to know and to conceive modernity? We believe that this happened during the phase in which the author participated in Naturalism - a social movement that had a strong impact on German society and culture. We argue that Simmel was strongly influenced by Naturalism, as many aspects of his theoretical and methodological ideas depend directly on the concept of modernity in the sense given to it by Naturalism. 